Quim. Nova, Vol. 34, No. 7, 1152-1156, 2011

\title{
SÍNTESE E CARACTERIZAÇÃO DE ARGILAS ORGANOFÍLICAS CONTENDO DIFERENTES TEORES DO SURFACTANTE CATIÔNICO BROMETO DE HEXADECILTRIMETILAMÔNIO
}

\author{
Christian Wittee Lopes* e Fábio G. Penha \\ Departamento de Química, Universidade Regional Integrada do Alto Uruguai e das Missões, Campus Erechim, Av. Sete de \\ Setembro, 1621, 99700-000 Erechim - RS, Brasil \\ Renata Martins Braga, Dulce Maria de Araújo Melo e Sibele B. C. Pergher \\ Departamento de Química, Universidade Federal do Rio Grande do Norte, Av. Senador Salgado Filho, 3000, Campus Universitário, \\ 59078-970 Natal - RN, Brasil \\ Diego Ivan Petkowicz \\ Instituto de Química, Universidade Federal do Rio Grande do Sul, CP 15003, 91501-970 Porto Alegre - RS, Brasil \\ Recebido em 26/8/10; aceito em 16/2/11; publicado na web em 15/4/11

\begin{abstract}
SYNTHESIS AND CHARACTERIZATION OF ORGANOCLAYS USING DIFFERENTS CONTENTS OF CATIONIC SURFACTANT HEXADECYLTRIMETHYLAMMONIUM BROMIDE. The major applications of organoclays are in adsorption of organic polluents. The objective of this work was the synthesis and characterization of organoclays using differents amounts of cationic surfactant hexadecyltrimethylammonium bromide. The clays were characterized by low angle x-ray diffraction (XRD), scanning electron microscope (SEM), infrared with Fourier tranformation (FTIR), BET surface area, elemental analysis (CHN), Foster swell and adsorption of methylene blue. The surfactant can adsorb in differents forms in the interlamelar region changed the basal spacing. The presence of the surfactant adsorbed can be favorable or not in adsorption of the methylene blue due the different interactions dye-organoclays.
\end{abstract}

Keywords: organoclays; surfactants; adsorption.

\section{INTRODUÇÃO}

O termo argila permite várias definições dependendo da área de concentração estudada (mineralogia, química, petrologia, sedimentologia, cerâmica), quer seja pela aplicação, quer seja pelas suas propriedades. ${ }^{1,2}$ Entretanto, a definição com maior aceitação, considera argila como uma rocha constituída essencialmente por minerais argilosos, podendo apresentar outros minerais (não argilosos), além de matéria orgânica e outras impurezas, que quando pulverizada e misturada com água em quantidade adequada se torna plástica. Após secagem, torna-se consistente e rígida, e após queima em temperatura superior a 1000 ${ }^{\circ} \mathrm{C}$, adquire grande dureza. ${ }^{1}$

Bentonita é uma argila que contém a montmorillonita como argilomineral mais abundante, pertencente ao grupo das esmectitas. Pertence ao grupo dos filossilicatos 2:1 e possui estrutura constituída por duas folhas tetraédricas de sílica com uma folha central octaédrica de alumina, que são unidas entre si por átomos de oxigênio que são comuns a ambas as folhas. Entre essas folhas encontram-se cátions trocáveis $\left(\mathrm{Na}^{+}, \mathrm{Ca}^{++}, \mathrm{Li}^{+}\right.$, etc) fixos eletrostaticamente com função de compensar carga, oriundos de substituições isomórficas como, por exemplo, $\mathrm{Si}^{+4}$ por $\mathrm{Al}^{+3}$ na camada tetraédrica e $\mathrm{Al}^{+3}$ por $\mathrm{Mg}^{+2}$ na camada octaédrica..$^{3-5}$

Os cátions trocáveis presentes no espaço interlamelar conferem às argilas propriedades de troca catiônica, isto é, os cátions podem ser trocados por outros cátions presentes em solução aquosa sem que a estrutura cristalina da argila se modifique, dando à argila propriedades de adsorção. Trocando os cátions interlamelares da argila por cátions orgânicos como, por exemplo, surfactantes, o caráter da argila é modificado de hidrofílica para hidrofóbica e a argila pode ser denominada como

*e-mail: christian.wl@hotmail.com argila organofílica, sendo capaz de adsorver compostos orgânicos. ${ }^{6-10}$

As argilas organofílicas são matérias-primas de elevado valor agregado para uma infinidade de aplicações industriais. A maior parte das argilas organofílicas usadas no Brasil são importadas. Elas podem ser aplicadas nas indústrias de tintas, graxas e resinas de poliéster, também usadas como adsorventes de compostos orgânicos, nanocompósitos poliméricos, fluidos tixotrópicos contendo líquidos não aquosos para perfuração de poços de petróleo., 8,11,12

Este trabalho teve por objetivo sintetizar e caracterizar argilas organofílicas modificadas com diferentes quantidades do surfactante catiônico brometo de hexadeciltrimetilamônio (HDTMA).

\section{PARTE EXPERIMENTAL}

A argila estudada era proveniente de Içara, estado de Santa Catarina. Trata-se de uma argila bentonítica, sem nenhum processo de purificação e com a montmorillonita como argilomineral mais abundante. Sua capacidade de troca catiônica (CTC) é da ordem de 179 meq/100 g de argila. É uma argila policatiônica, possuindo $\mathrm{Ca}^{++}$e $\mathrm{Mg}^{++}$no seu espaço interlamelar.

\section{Preparação das argilas organofílicas (AO)}

As argilas organofílicas foram preparadas seguindo a metodologia ${ }^{5}$ descrita por Kozak e Domka. Neste procedimento é preparada uma suspensão de argila em água. Após, é adicionada a suspensão a solução de surfactante em água. No experimento foram sintetizadas argilas organofílicas com diferentes teores em massa de surfactante que foram: 1:10; 2:10; 4:10 e $8 \mathrm{~g}: 10 \mathrm{~g}$ de surfactante argila. Posteriormente, a suspensão foi deixada em refluxo a $80^{\circ} \mathrm{C}$ sob agitação durante $20 \mathrm{~h}$. 


\section{Caracterização das argilas organofílicas}

As argilas organofílicas foram caracterizadas por um conjunto de técnicas: análise elementar $\mathrm{CHN}$, área específica pelo método BET, espectroscopia vibracional da região do infravermelho com transformada de Fourier (FTIR), difração de raios X a baixo ângulo (SAXS), microscopia eletrônica de varredura (SEM), inchamento de Foster e adsorção de azul de metileno.

\section{Análise elementar (CHN)}

As análises de $\mathrm{CHN}$ foram realizadas em um analisador Perkin Elmer M CHNS/O modelo 2400. A massa de amostra utilizada para cada análise foi em torno de $2 \mathrm{mg}$.

\section{Área específica}

As medidas de área específica foram realizadas por adsorção de nitrogênio, utilizando o aparelho QuantaChrome Nova 2200e.

\section{Espectroscopia vibracional na região do infravermelho com} transformada de Fourier (FTIR)

Os dados foram obtidos em um espectrofotômetro FTIR Shimadzu modelo 8300. Todos os espectros foram coletados no intervalo $4000-400 \mathrm{~cm}^{-1}, 32$ varreduras e resolução de $4 \mathrm{~cm}^{-1}$. Para análise de infravermelho foram preparadas pastilhas dos materiais com o uso de um pastilhador e uma prensa hidráulica manual. Na análise dos materiais obtidos foram preparadas pastilhas de aproximadamente $0,5 \mathrm{~mm}$ de espessura e $5 \mathrm{~mm}$ de diâmetro. A diluição (cerca de $10 \%$ de amostra) foi realizada em $\mathrm{KBr}$.

\section{Difratometria de raios- $X$ a baixo ângulo (SAXS)}

As análises por difração de raios $X$ a baixo ângulo foram realizadas em um Siemens D500 com monocromador de grafite utilizando radiação $\operatorname{CuK} \alpha(\lambda=1,54 \AA)$. As análises foram realizadas em ângulo de 2 teta $\left(1\right.$ a $\left.10^{\circ}\right)$ utilizando um tubo de raios $X$, voltagem de 30,0 $\mathrm{kV}$ e corrente de $30,0 \mathrm{~mA}$.

\section{Microscopia eletrônica de varredura (SEM)}

As amostras foram recobertas com ouro e analisadas num microscópio eletrônico de varredura modelo XL-30 ESEM (Phillips).

\section{Inchamento de Foster}

O ensaio consistiu em adicionar, lentamente e sem agitação, $1,0 \mathrm{~g}$ de argila organofílica em $50 \mathrm{~mL}$ do solvente contido em proveta de $100 \mathrm{~mL}$. Em seguida, o sistema foi deixado em repouso por $24 \mathrm{~h}$. Decorrido o tempo de repouso, mediu-se o volume ocupado pela argila (inchamento sem agitação). Logo após, agitou-se o conteúdo da proveta, com bastão de vidro, por $5 \mathrm{~min}$, deixando novamente o sistema em repouso. Após 24 h de repouso, mediu-se o volume ocupado pela argila (inchamento com agitação). Os solventes orgânicos testados foram etanol, diesel comercial, gasolina comercial, tolueno P.A, acetona P.A. ${ }^{13,14}$

\section{Adsorção de azul de metileno}

Os estudos de adsorção do azul de metileno sobre as argilas foram realizados em banho termostatizado a $25^{\circ} \mathrm{C}$, deixando em contato 0,1 g da argila natural e orgânica em $50 \mathrm{~mL}$ de diferentes concentrações $\left(1,0 \times 10^{-5}\right.$ a $\left.1,0 \times 10^{-2} \mathrm{~mol} / \mathrm{L}\right)$ do corante por um período de $2 \mathrm{~h}$.

\section{RESULTADOS E DISCUSSÃO}

A Figura 1 mostra os difratogramas da argila natural e das argilas organofílicas (AO) sintetizadas com diferentes quantidades do surfactante, a $80{ }^{\circ} \mathrm{C}$ em refluxo com agitação. As quantidades de surfactante foram: 1,0 g (AO $1 \mathrm{~g}$ ); 2,0 g (AO $2 \mathrm{~g}$ ); 4,0 g (AO $4 \mathrm{~g}$ ) e $8,0 \mathrm{~g}$ (AO $8 \mathrm{~g}$ ). Pelo pico da argila natural em $2 \theta=5,75$ trata-se de um argilomineral tipo montmorillonita da família 2:1, ou seja, formada por duas lâminas $\mathrm{T}$ e uma lâmina $\mathrm{O}$.

Os argilominerais do tipo montmorillonita são expansíveis, ou seja, a distância interlamelar pode variar dependendo do tamanho da molécula adsorvida. A expansão pode ser acompanhada pela variação no ângulo de difração $\mathrm{d}_{001}$ característico desse argilomineral. De acordo com a lei de Bragg, $n \lambda=2 d \operatorname{sen} \theta$, o ângulo de difração $\theta$ e a distância interatômica $\mathrm{d}$ responsável pela difração são inversamente proporcionais. Portanto, uma diminuição no ângulo de difração $\mathrm{d}_{001}$ indica a expansão interlamelar do argilomineral. Os difratogramas da Figura 1 indicam variações no ângulo e no $\mathrm{d}_{001}$; observa-se também a presença de dois picos, dependendo da quantidade de surfactante usado na preparação das argilas organofílicas. A presença de dois picos pode ser indicativa da formação de diferentes espaçamentos

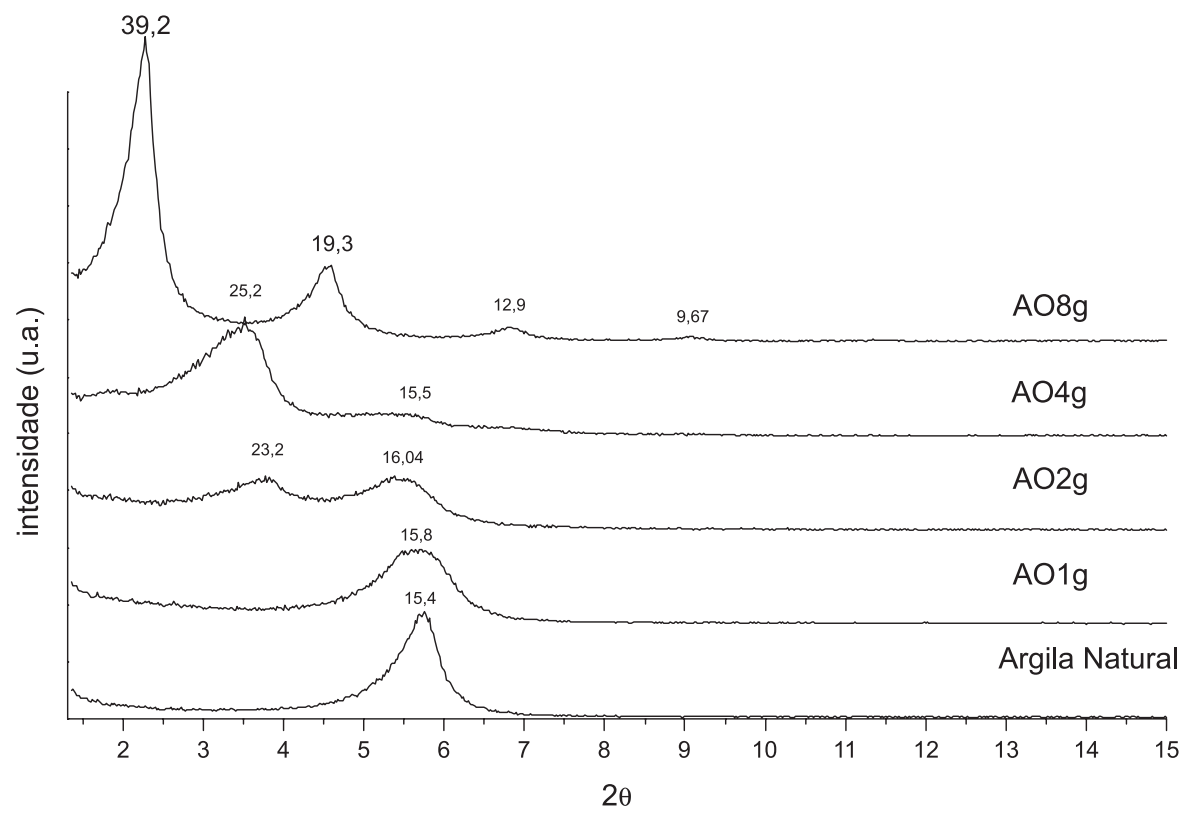

Figura 1. Difratogramas de raios X a baixo ângulo da argila natural e das argilas organofílicas 
basais. ${ }^{9}$ A Tabela 1 resume os valores de $2 \theta$ e os respectivos valores de $\mathrm{d}_{001}, \mathrm{~d}_{002}$ e $\mathrm{d}_{003}$.

Tabela 1. Valores de $2 \theta$ e seus respectivos $d_{001}$ para as argilas

\begin{tabular}{ccccccc}
\hline Argila & $2 \theta$ & $\mathrm{d}_{001}, \AA$ & $2 \theta$ & $\mathrm{d}_{002}, \AA$ & $2 \theta$ & $\mathrm{d}_{003}, \AA$ \\
\hline natural & 5,75 & 15,4 & - & - & - & - \\
$1 \mathrm{~g}$ & 5,64 & 15,8 & - & - & - & - \\
$2 \mathrm{~g}$ & 3,78 & 23,2 & 5,48 & 16,04 & - & - \\
$4 \mathrm{~g}$ & 3,52 & 25,2 & 5,77 & 15,5 & - & - \\
$8 \mathrm{~g}$ & 2,27 & 39,2 & 4,57 & 19,3 & 6,82 & 12,9 \\
\hline
\end{tabular}

Pelos resultados de SAXS podem-se propor alguns mecanismos de acomodação do surfactante no processo de adsorção sobre a argila, que depende da quantidade de surfactante utilizado na síntese. A Figura 2 ilustra de maneira simplificada as possibilidades sugeridas para a acomodação do surfactante sobre a argila.

Em (a) trata-se de um esquema da argila natural que é hidrofílica e, de acordo com a Tabela 1 e Figura 1, apresenta $2 \theta$ em 5,75 dando um $\mathrm{d}_{001}$ de $15,4 \AA$. A classificação da argila em hidrofílica ou hidrofóbica pode ser observada pela sua interação com a água. Em (b) tem-se a argila organofílica $\mathrm{AO} 1 \mathrm{~g}$, que é hidrofóbica devido à adsorção externa do surfactante, e o deslocamento de $2 \theta$ para 5,64 indica uma adsorção do surfactante entre as lamelas da argila com uma pequena expansão, com $\mathrm{d}_{001}$ de 15,8 $\AA$. Em (c) representam-se as duas espécies sugeridas para as argilas AO $2 \mathrm{~g}$ e AO $4 \mathrm{~g}$, ambas hidrofóbicas. Pelos difratogramas da Figura 1 nota-se a presença de dois picos para estas argilas, um pico em ângulo menor em torno de 3 , que é devido à argila mais expandida, com $\mathrm{d}_{001}$ próximo de $24,00 \AA$, e outro em ângulo maior em torno de 5 , devido à argila menos expandida, com $\mathrm{d}_{001}$ próximo de $16,00 \AA$. Em (d) tem-se a representação da argila organofílica $\mathrm{AO} 8 \mathrm{~g}$ que voltou a ser hidrofílica como a argila natural, devido à adsorção externa do surfactante sobre a argila com a formação de bicamadas, com a parte carregada do surfactante voltada para a solução aquosa. Nota-se que mesmo sendo uma argila organofílica pela presença do surfactante adsorvido, apresenta afinidade por água. Pelo difratograma da Figura 1, para a AO 8 g, nota-se além do pico em $2 \theta$ de 2,27, que é devido à acomodação do surfactante entre as lamelas da argila e sua expansão para $39,2 \AA$, que existe a presença de um pico em $2 \theta$ de 4,57 dando um de $19,3 \AA$, referente ao $\mathrm{d}_{002}$ da argila e ainda um pico em 6,82 , dando um espaçamento de $12,9 \AA$, referente ao $\mathrm{d}_{003}$. Na Tabela 2 estão apresentados os resultados de análise elementar (CHN), onde se mostra que a quantidade de carbono, hidrogênio e nitrogênio aumenta com a quantidade de surfactante no meio, e também se confirma a presença do surfactante na argila. A argila contém matéria orgânica, então o valor de carbono pode estar relacionado a isso. No momento da análise pode estar com águas de hidratação devido à umidade, portanto, o valor de hidrogênio pode estar relacionado a isso. $\mathrm{O}$ nitrogênio é o único elemento que possi- velmente pode estar sendo relacionado à inserção do surfactante no meio, pois, de acordo com a análise, não contém na amostra da argila natural. O surfactante HDTMA possui 3,84\% de nitrogênio em sua formulação e, de acordo com cálculos matemáticos, $0,27 \%$ da amostra AO $1 \mathrm{~g}$ corresponde a 7,03\% de surfactante inserido. O mesmo vale para as outras amostras, com valores de $16,92 \%$ para a argila AO 2 g, 25,52\% para a amostra AO 4 g e 44,27\% para a amostra AO 8 g. Isto confirma a inserção do surfactante no meio.

Tabela 2. Análise elementar $(\mathrm{C}, \mathrm{H}, \mathrm{N})$ das amostras

\begin{tabular}{cccc}
\hline Amostra & $\mathrm{C}$ & $\mathrm{H}$ & $\mathrm{N}$ \\
\hline Argila natural & $0,18 \%$ & $2,25 \%$ & $-0,02 \%$ \\
$1 \mathrm{~g}$ & $6,22 \%$ & $2,43 \%$ & $0,27 \%$ \\
$2 \mathrm{~g}$ & $12,47 \%$ & $3,3 \%$ & $0,65 \%$ \\
$4 \mathrm{~g}$ & $20,18 \%$ & $4,24 \%$ & $0,98 \%$ \\
$8 \mathrm{~g}$ & $31,04 \%$ & $6,02 \%$ & $1,7 \%$ \\
\hline
\end{tabular}

Na Tabela 3 estão apresentados os valores de área específica. Nota-se que as argilas organofílicas apresentam uma área específica menor quando comparadas com a argila natural e, também, ocorre uma diminuição da área com o aumento da quantidade de surfactante adsorvido sobre a argila. O surfactante impede a adsorção de moléculas de nitrogênio, diminuindo a área específica, comprovando sua inserção no espaço interlamelar.

Tabela 3. Área específica das argilas natural e organofílicas

\begin{tabular}{lc}
\hline Argila & Área superficial específica $\left(\mathrm{m}^{2} / \mathrm{g}\right)$ \\
\hline Natural & 63,00 \\
Organofílica 1 g & 12,88 \\
Organofílica 2 g & 6,76 \\
Organofílica 4 g & 6,54 \\
Organofílica 8 g & 4,85 \\
\hline
\end{tabular}

A Figura 3 apresenta a análise de espectroscopia vibracional na região do infravermelho com transformada de Fourier (FTIR) das argilas organofílicas e da argila natural. Comparando o espectro da argila natural com as orgânicas, notam-se variações significativas na região de $2921 \mathrm{~cm}^{-1}$, referente aos grupos $\mathrm{CH}_{2}$ da cadeia carbônica do surfactante adsorvido sobre a argila. Nota-se também que a intensidade desta vibração aumenta com o aumento da quantidade de surfactante presente na argila. A vibração em $1634 \mathrm{~cm}^{-1}$ é devida à presença de água adsorvida na argila, e na região de $1500 \mathrm{~cm}^{-1}$ é devida à presença do grupo $\mathrm{CH}_{3}$. Nota-se, portanto, uma diminuição da água adsorvida e um aumento do grupamento $\mathrm{CH}_{3}$ com o aumento da quantidade de surfactante adsorvido sobre a argila., ${ }^{75}$

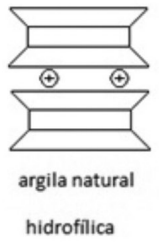

(a)

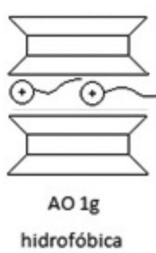

(b)

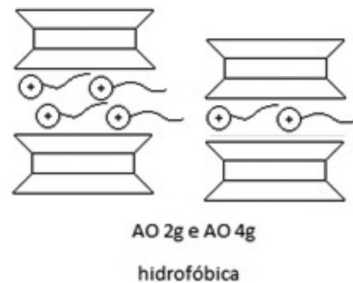

(c)
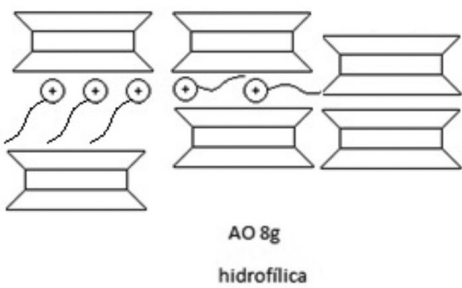

(d)

Figura 2. Possibilidades sugeridas para a acomodação do surfactante sobre a argila 


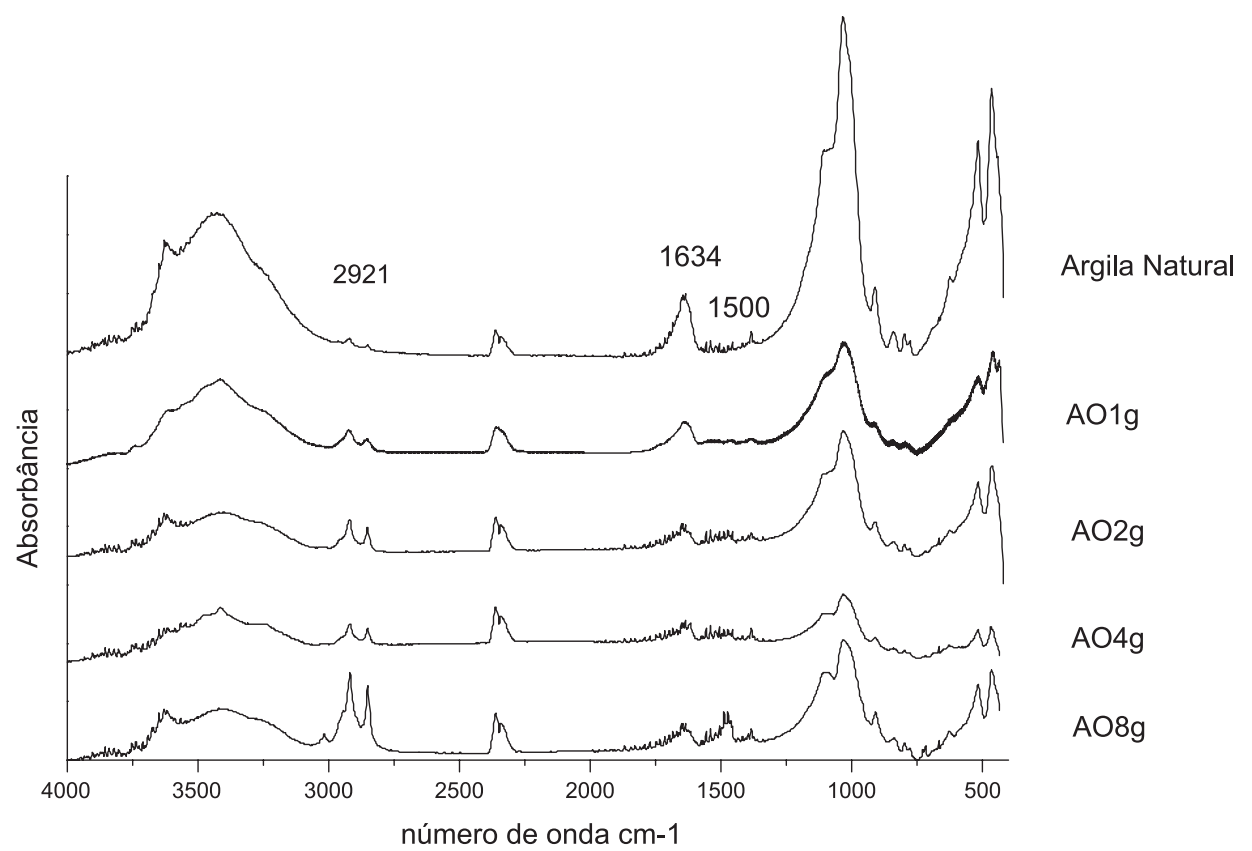

Figura 3. Espectroscopia vibracional na região do infravermelho com transformada de Fourier das amostras de argila natural e organofílicas

A Figura 4 mostra os resultados obtidos nos experimentos de inchamento de Foster para argilas natural e organofílicas, com e sem agitação, utilizando-se os solventes etanol, acetona, diesel, gasolina e tolueno.

\section{Inchamento de Foster}
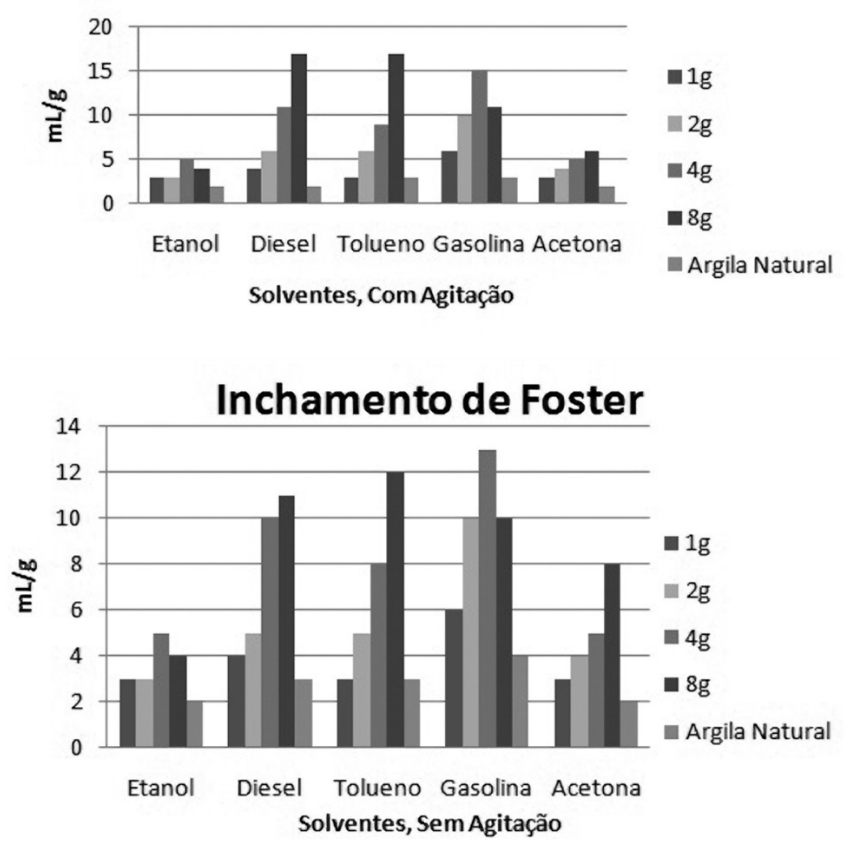

Figura 4. Testes de inchamento de Foster, com e sem agitação

O maior inchamento observado foi para a argila AO $8 \mathrm{~g}$ com agitação utilizando-se os solventes diesel e tolueno, que foi de 17 $\mathrm{mL} / \mathrm{g}$, um valor considerado alto. ${ }^{14}$ Este comportamento é explicado pela maior quantidade de surfactante adsorvido sobre a argila. As análises de CHN indicam 31,04\% de C, tratando-se da argila com características mais organofílicas preparadas. Para estes solventes observa-se um aumento no inchamento com o aumento da quantidade de surfactante no meio e, consequentemente, um aumento da quan- tidade de carbono sobre a argila. Isto possibilita uma maior retenção de solventes apolares, como o diesel e o tolueno, pela argila orgânica. A agitação favorece a retenção dos solventes na argila; sem agitação o inchamento discutido cai para $12 \mathrm{~mL} / \mathrm{g}$.

O menor inchamento foi observado para o etanol, um solvente polar, e não houve variações significativas entre as argilas orgânicas e nem com a agitação do meio.

A Figura 5 apresenta as análises de microscopia eletrônica de varredura (SEM) da argila natural juntamente com uma argila organofílica. Em (a) tem-se a imagem da argila natural, e em (b) da organofílica com $2 \mathrm{~g}$ de surfactante. As análises demonstram uma morfologia lamelar característica dos argilominerais do tipo montmorillonita. A argila natural apresenta espaços e aglomerados pequenos quando comparada com a orgânica $2 \mathrm{~g}$, que apresenta aglomerados grandes. As argilas organofílicas $1 \mathrm{~g}, 4 \mathrm{~g}$ e $8 \mathrm{~g}$ se encontram nas Figuras $1 \mathrm{~S}, 2 \mathrm{~S}$ e $3 \mathrm{~S}$, respectivamente, do material suplementar.

O gráfico da Figura 6 mostra as isotermas de adsorção do corante do azul de metileno sobre a argila natural e as argilas organofílicas. As isotermas indicam a quantidade de corante adsorvido, q, em função da concentração do corante no equilíbrio, Ceq, a uma temperatura constante de $25{ }^{\circ} \mathrm{C}$.

A presença do surfactante adsorvido pode favorecer ou desfavorecer a adsorção do corante. A tendência observada é que o processo de adsorção do corante é favorecido utilizando-se menores quantidades do surfactante ( 2 e $4 \mathrm{~g}$ ) em comparação com a argila natural e com $8 \mathrm{~g}$ de surfactante.

Estes resultados de adsorção estão de acordo com o mecanismo proposto, pela Figura 2, de acomodação do surfactante sobre a argila. O processo de adsorção do corante (catiônico) sobre a argila natural se dá por troca catiônica dos cátions de compensação interlamelar (como $\mathrm{Na}^{+}$) com o corante. A presença do surfactante $(2 \mathrm{e} 4 \mathrm{~g}$ ) favorece a adsorção, pois as interações hidrofóbicas surfactante-corante estarão agora presentes. O desfavorecimento na adsorção do corante usando-se $8 \mathrm{~g}$ de surfactante está de acordo com o mecanismo de adsorção de surfactantes catiônicos sobre silicatos, ${ }^{16} \mathrm{em}$ que em altas concentrações de surfactante ocorre a formação de bicamadas com a parte carregada voltada para a solução, inibindo a adsorção do corante catiônico por repulsão. 

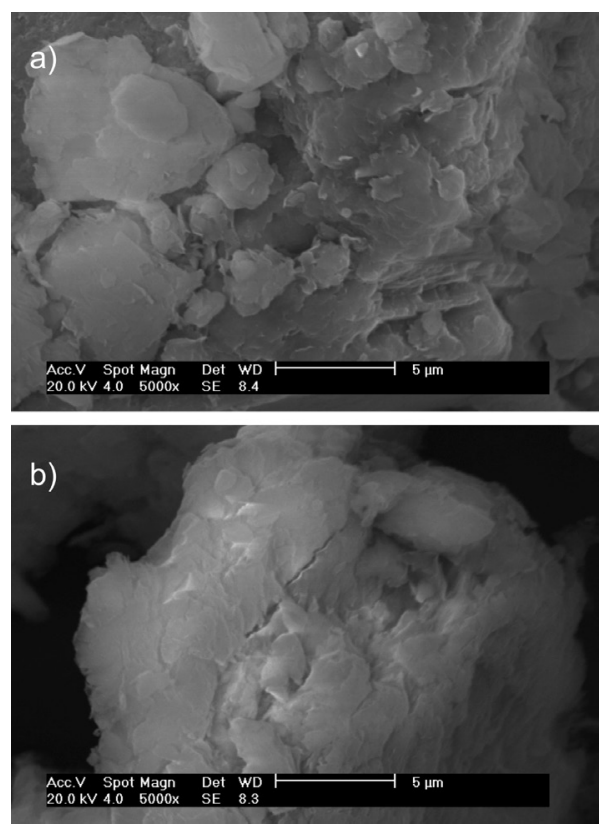

Figura 5. Micrografias das argilas: (a) argila natural, (b) argila organofilica $-2 g$

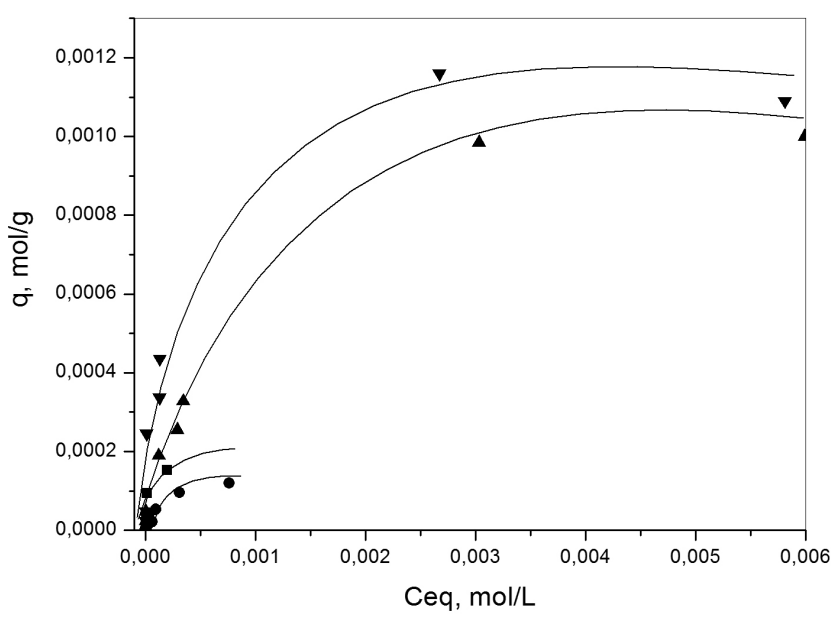

Figura 6. Isotermas de adsorção a $25^{\circ} \mathrm{C}$ : $\bullet$ argila natural; $\bullet \mathrm{AO} 8 \mathrm{~g} ; \mathbf{\Delta} \mathrm{AO}$ $4 \mathrm{~g} ; \boldsymbol{\nabla} \mathrm{AO} 2 \mathrm{~g}$

\section{CONCLUSÕES}

Argilas organofílicas foram sintetizadas com o surfactante catiônico brometo de hexadeciltrimetilamônio (HDTMA). A quantidade de surfactante usada na síntese interferiu nas características de molhabilidade da argila obtida, devido à acomodação do surfactante de diferentes formas. Utilizando 1,0,2,0 e 4,0 g de surfactante na síntese, a argila organofílica é hidrofóbica devido às cadeias carbônicas do surfactante ficarem voltadas para a solução aquosa. Aumentando a quantidade de surfactante para 8,0 g, a argila volta a ser hidrofílica como a natural, devido à adsorção do surfactante em bicamadas com a parte carregada voltada para a solução. Análises por DRX a baixo ângulo mostram que o surfactante pode se acomodar de diferentes formas na região interlamelar, variando o espaçamento basal $\mathrm{d}_{001}$. Houve uma diminuição da área específica das argilas organofílicas em relação à argila natural, devido à presença do surfactante adsorvido. A análise $\mathrm{CHN}$ confirmou a presença do surfactante na argila, sendo que a porcentagem de carbono aumentou com a quantidade de surfactante no meio. A presença do surfactante sobre a argila também foi confirmada por FTIR. As imagens de SEM mostram uma morfologia lamelar característica da argila; a morfologia teve pouca alteração, quando modificada pelo surfactante se notou apenas a formação de aglomerados. As argilas foram testadas com a remoção do corante azul de metileno de uma solução aquosa. A presença do surfactante adsorvido pode favorecer ou desfavorecer a adsorção do corante, devido à atração ou repulsão predominar no sistema corante-argila orgânica.

\section{MATERIAL SUPLEMENTAR}

Disponível em http://quimicanova.sbq.org.br, na forma de arquivo PDF, com acesso livre.

\section{AGRADECIMENTOS}

À URI-Campus de Erechim. Aos projetos CTPETRO-INFRA I e FINEP/LIEM da UFRN pelas análises de MEV.

\section{REFERÊNCIAS}

1. Souza Santos, P. de.; Tecnologia de Argilas, vol 1, Edgard Blucher, Ed da Universidade de São Paulo, São Paulo, 1975.

2. Coelho, A. C. V.; Souza Santos, P. de.; Quim. Nova 2007, 30, 146.

3. Rodríguez-Sarmiento, D. C.; Pinzón-Bello, J. A.; Appl. Clay Sci. 2001, $18,173$.

4. Leite, I. F.; Raposo, C. M. O.; Silva, S. M. J.; Cerâmica 2008, 54, 303.

5. Kozak, M.; Domka, L.; J. Phys Chem Solids 2004, 65, 441.

6. Vazquez, A.; López, M.; Kortaberria, G.; Martín, L.; Mondragon, I.; Appl. Clay Sci. 2008, 41, 24.

7. Paiva, L. B.; Morales, A. R.; Díaz, F. R. V.; Appl. Clay Sci. 2008a, 42, 8.

8. Teixeira-Neto, E.; Teixeira-Neto, A. A.; Quim. Nova 2009, 32, 809.

9. Paiva, L. B.; Morales, A. R.; Díaz, F. R. V.; Cerâmica 2008b, 54, 213.

10. Froehner, S.; Martins, R. F.; Furukawa, W.; Errera, M. R.; Water, Air, Soil Pollut. 2009, 199, 107.

11. He, H.; Frost, R.L.; Bostrom, T.; Yuan, P.; Duong, L.; Yang, D.; Xi, Y.; Kloprogge, J. T.; Appl. Clay Sci. 2006, 31, 262.

12. Yilmaz, N.; Yapar, S.; Appl. Clay Sci. 2004, 27, 223.

13. Foster, M. D.; Am. Mineral. 1953, 38, 994.

14. Pereira, K. R. O.; Rodrigues, M. G. F.; Diaz, F. R. V.; Rev. Elet. Mat. Proc. 2007, 2.2, 1.

15. Frost, R. L.; Zhou, Q.; He, H.; Yunfei, X.; Spectrochim. Acta, Part A 2008, 69, 239.

16. Atkin, R.; Craig, V.S.J.; Wanless, E.J.; Biggs, S.; Adv. Colloid Interface Sci. 2003, 103, 219. 


\section{SÍNTESE E CARACTERIZAÇÃO DE ARGILAS ORGANOFÍLICAS CONTENDO DIFERENTES TEORES DO SURFACTANTE CATIÔNICO BROMETO DE HEXADECILTRIMETILAMÔNIO}

\section{Christian Wittee Lopes* e Fábio G. Penha}

Departamento de Química, Universidade Regional Integrada do Alto Uruguai e das Missões, Campus Erechim, Av. Sete de Setembro, 1621, 99700-000 Erechim - RS, Brasil

Renata Martins Braga, Dulce Maria de Araújo Melo e Sibele B. C. Pergher

Departamento de Química, Universidade Federal do Rio Grande do Norte, Av. Senador Salgado Filho, 3000, Campus Universitário, 59078-970 Natal - RN, Brasil

Diego Ivan Petkowicz

Instituto de Química, Universidade Federal do Rio Grande do Sul, CP 15003, 91501-970 Porto Alegre - RS, Brasil

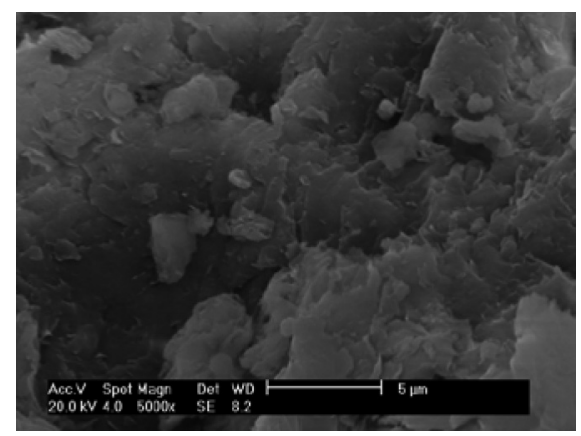

Figura 1S. Micrografia da argila organofílica $-1 \mathrm{~g}$

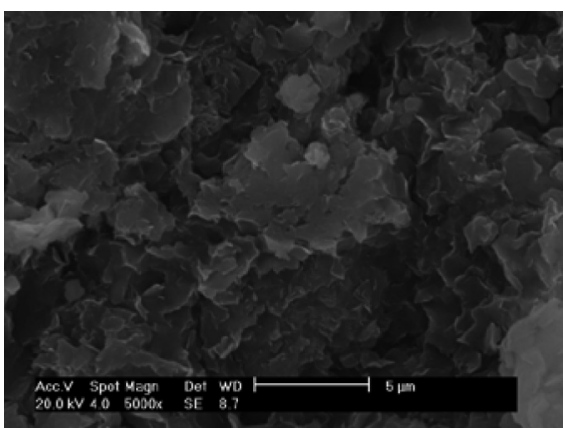

Figura 2S. Micrografia da argila organofílica - $4 \mathrm{~g}$

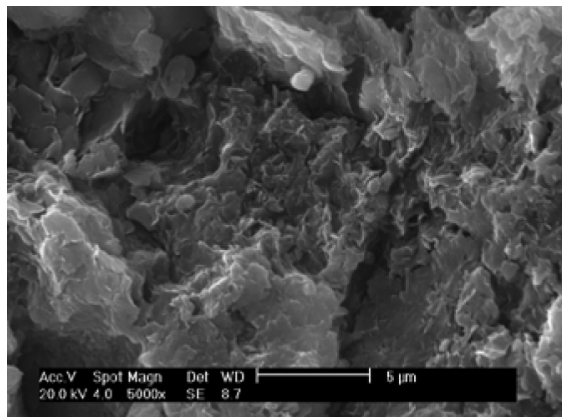

Figura 3S. Micrografia da argila organofílica $-8 g$ 